\title{
Mutant PIK3CA controls DUSP1-dependent ERK $1 / 2$ activity to confer response to AKT target therapy
}

\author{
A Sathe ${ }^{1}$, F Guerth ${ }^{1}$, M V Cronauer ${ }^{2}$, M M Heck ${ }^{1}, M$ Thalgott ${ }^{1}$, J E Gschwend ${ }^{1}$, M Retz ${ }^{1}$ and R Nawroth ${ }^{*}, 1$ \\ ${ }^{1}$ Department of Urology, Klinikum rechts der Isar, Technische Universität München, Ismaninger Strasse 22, Munich 81675, Germany \\ and ${ }^{2}$ Department of Urology, Ulm University Medical Center, Prittwitzstrasse 43, Ulm 89075, Germany
}

Background: Alterations in the phosphoinositide 3-kinase/AKT/mammalian target of rapamycin (PI3K/AKT/mTOR) signalling pathway are frequent in urothelial bladder cancer (BLCA) and thus provide a potential target for novel therapeutic strategies. We investigated the efficacy of the AKT inhibitor MK-2206 in BLCA and the molecular determinants that predict therapy response.

Methods: Biochemical and functional effects of the AKT inhibitor MK-2206 were analysed on a panel of 11 BLCA cell lines possessing different genetic alterations. Cell viability (CellTiter-Blue, cell counts), apoptosis (caspase 3/7 activity) and cell cycle progression (EdU incorporation) were analysed to determine effects on cell growth and proliferation. cDNA or siRNA transfections were used to manipulate the expression of specific proteins such as wild-type or mutant PIK3CA, DUSP1 or CREB. For in vivo analysis, the chicken chorioallantoic membrane model was utilised and tumours were characterised by weight and biochemically for the expression of Ki-67 and AKT phosphorylation.

Results: Treatment with MK-2206 suppressed AKT and S6K1 but not 4E-BP1 phosphorylation in all cell lines. Functionally, only cell lines bearing mutations in the hotspot helical domain of PIK3CA were sensitive to the drug, independent of other genetic alterations in the PI3K or MAPK signalling pathway. Following MK-2206 treatment, the presence of mutant PIK3CA resulted in an increase in DUSP1 expression that induced a decrease in ERK 1/2 phosphorylation. Manipulating the expression of mutant or wildtype PIK3CA or DUSP1 confirmed that this mechanism is responsible for the induction of apoptosis and the inhibition of tumour proliferation in vitro and in vivo, to sensitise cells to AKT target therapy.

Conclusion or interpretation: PIK3CA mutations confer sensitivity to AKT target therapy in BLCA by regulating DUSP1 expression and subsequent ERK1/2 dephosphorylation and can potentially serve as a stratifying biomarker for treatment.

The phosphoinositide 3-kinase/AKT/mammalian target of rapamycin (PI3K/AKT/mTOR) signalling pathway has a fundamental role in tumourigenesis and tumour progression. Molecular alterations resulting in the hyperactivation of this pathway have been observed frequently in human cancer making it particularly suited for targeted therapy (Yuan and Cantley, 2008). Chemical inhibitors targeting different molecules in this pathway have been developed, but their clinical implementation has had limited success (Rodon et al, 2013). This might be explained by the underlying tumour genetics as well as the complex network of feedback loops in this signalling pathway that rescues their inhibitory effects (Weigelt and Downward, 2012; Klempner et al, 2013).

Activated PI3K regulates PDK1- and mTORC2-mediated phosphorylation of AKT, which is an oncogenic serine/ threonine kinase with the three isoforms AKT 1, 2 and 3, a mechanism that can be reversed by PTEN (Manning and Cantley, 2007). AKT can induce different cellular responses such as proliferation and growth, cell cycle progression, apoptosis, metabolism, metastasis, invasion and angiogenesis. One of its 
downstream targets is the mTORC1 protein complex that is involved in controlling protein translation by regulating the proteins S6K1 and 4E-BP1. Upon treatment of cells with mTOR inhibitors, AKT is reactivated via molecular feedback loops that might protect the cell from therapeutic effects (Sun et al, 2005; O'Reilly et al, 2006; Nawroth et al, 2011). AKT has emerged as a potential target molecule in cancer therapy. Several pharmacologically distinct inhibitors possessing varying affinities towards the different AKT isoforms have been developed (Mattmann et al, 2011) and are currently being tested in more than 150 registered clinical trials in different tumour entities (U.S. National Library of Medicine Clinical Trials, 2014a).

One such well-characterised inhibitor in early-phase clinical trials is MK-2206, an allosteric AKT inhibitor that targets all three isoforms (Yap et al, 2011). Preclinical data in various tumour entities suggest that it is effective only in a subset of tumours possessing specific molecular alterations in PI3K or MAPK signalling. However, these alterations that are associated with sensitivity are not uniform across various tumour types suggesting that distinct molecular patterns, specific for a particular tumour entity might predict response to therapy (Meng et al, 2010; Liu et al, 2011; Sangai et al, 2012). Thus, the complexity behind the signalling events that contribute to the selective efficacy of AKT inhibition in the presence of specific genetic alterations remains to be understood. MK-2206 is now being tested in phase II trials in which patients are pre-stratified for PIK3CA, AKT or PTEN mutations in breast and lung cancer or thymic malignancies, those with KRAS wild type (WT) and PIK3CA mutations in metastatic colorectal cancer, or PIK3CA mutations in advanced endometrial cancer (U.S. National Library of Medicine Clinical Trials, 2014b, c, d, e).

In this preclinical study, we have focused on the characterisation of AKT target therapy in urothelial bladder cancer (BLCA). BLCA is the ninth most common cancer worldwide with more than 330000 new patients each year, of which around 30\% are clinically advanced with either muscle invasive or metastatic disease (Witjes et al, 2013). The current recommended treatment for patients with non-organ-confined muscle-invasive disease is radical cystectomy and lymphadenectomy, combined with neoadjuvant chemotherapy, which provides a 5 -year survival of $50-55 \%$. However, around $50 \%$ of these patients relapse, and of these, about $70 \%$ present with distant metastases. Advanced BLCA has a dismal prognosis with first-line chemotherapy regimens of methotrexate, vinblastine, doxorubicin and cisplatin (MVAC) or gemcitabine plus cisplatin (GC) providing a modest survival of around 14 months (von der Maase et al, 2000). The only approved second-line agent vinflunine provides just a 2-month survival advantage (Bellmunt et al, 2013). These treatment strategies and overall prognosis have remained largely unchanged over the last 25 years.

About $50-70 \%$ of BLCA tumours possess molecular alterations that affect $\mathrm{PI} 3 \mathrm{~K} / \mathrm{AKT} / \mathrm{mTOR}$ signalling, including activating PIK3CA mutations in 20-25\%, inactivating TSC1 mutations in $8-16 \%$ and inactivating PTEN mutations or loss of expression in 13-16\% (Knowles et al, 2009; Ciriello et al, 2013; Cancer Genome Atlas Research Network, 2014). These tumours might stand to benefit from target therapy against the PI3K signalling pathway. Different clinical trials for patients with advanced BLCA were initiated with mTORC1 inhibitors (rapalogues) in recent years. However, the results from these trials have been disappointing with only up to $20-30 \%$ of patients showing a clinical benefit (Gerullis et al, 2011; Seront et al, 2012; Milowsky et al, 2013). A potential association between the presence of TSC1 mutations and response to rapalogues in BLCA has been reported and demonstrates that a thorough understanding of the signalling events initiated by the $\mathrm{PI} 3 \mathrm{~K} / \mathrm{AKT} / \mathrm{mTOR}$ pathway is required to maximise the potential benefit of available inhibitors in patients (Iyer et al, 2012).

It has been previously demonstrated, that the use of rapalogues and also dual PI3K/mTOR inhibitors in BLCA triggers feedback loops that hyperphosphorylate AKT, suggesting that AKT might be a key molecule in regulating tumour growth in BLCA (Nawroth et al, 2011). Consequently, we set out to determine the in vitro and in vivo response of BLCA tumour models to AKT inhibition and the molecular determinants and mechanisms involved in mediating and predicting responsiveness to AKT target therapy.

\section{MATERIALS AND METHODS}

Cell lines and cell culture. Cell lines HT1197, HT1376, RT4, UMUC3, J82 and T24 were obtained from the American type culture collection (Manassas, VA, USA), RT112 and 647V from the Leibniz institute German collection of microorganisms and cell cultures (Braunschweig, Germany), 253J were a kind gift from Professor Dr G. Unteregger (University of Saarland, Homburg/ Saar, Germany) and 639 V and VmCUB1 were kindly provided by Professor Dr WA Schulz (Heinrich-Heine-University, Düsseldorf, Germany). Cells were maintained as early passages of subconfluent cultures in RPMI or DMEM (Biochrom AG, Berlin, Germany) at $5 \%$ or $10 \% \mathrm{CO} 2$, respectively, supplemented with $10 \%$ FBS (Biochrom AG) and 1\% NEAA (Biochrom AG). A total of $1 \times 10^{6}, 1 \times 10^{5}$ or $2 \times 10^{5}$, and 1000 or 8000 cells were seeded in $10 \mathrm{~cm}, 6$-well and 96-well formats, respectively.

Small molecule inhibitor and treatment. MK-2206 (Active Biochem, Bonn, Germany) was stored as a $10 \mathrm{~mm}$ stock solution in DMSO and working concentrations were freshly prepared in medium. As a control, DMSO was used corresponding to the DMSO in the highest MK-2206 concentration.

siRNA oligonucleotides and transfection. Ten nanomolar of stealth RNAi oligonucleotides (Life Technologies, Darmstadt, Germany) against AKT1 (UGCAGCAUCGCUUCUUUGCCGGUAU, GACG UGGCUAUUGUGAAGGAGGGUU), AKT2 (GGCACGGGCTA AAGTGACCATGAAT, CCUUGGCAAGGGAACCUUUGGCAAA), AKT3 (GGCACACACUCUAACUGAAAGCAGA, ACCTCAAGATGTGGATTTACCTTAT), PIK3CA (AAGAGCCCCGAGCG UUUCUGCUUUU targeting the 5'UTR), DUSP1 (GCCAUUGAC UUCAUAGACUCCAUCA), negative control Hi GC duplex \#2, and Silencer siRNA (Life Technologies) for CREB (GCUGGCUAA CAAUGGUACCtt) were used for transfecting cells with Lipofectamine RNAimax (Life Technologies) according to the manufacturer's instructions. All assays were conducted 48 or $72 \mathrm{~h}$ after transfection.

Plasmid construction and transfection. The HA PIK3CA E545K fragment from pBABE puro HA PIK3CA E545K (Addgene, Cambridge, MA, USA) (plasmid number 12525) (Zhao et al, 2005) was cloned into pcDNA3.1/V5-His-TOPO (Life Technologies) and verified by sequencing. QiaQuick Gel extraction kit and Qiagen Plasmid Midi kit (Qiagen, Hilden, Germany) were used as per the manufacturer's protocol. pCMV2-Tag 2A PIK3CA-WT was purchased from Addgene (plasmid number 16643) (Samuels et al, 2004) and verified by sequencing. pcDNA3.1/V5-his-TOPO was used as a control. Cells were transfected using FuGENE HD (Promega Corporation, Madison, WI, USA) according to the manufacturer's instructions. siRNA and DNA co-transfection was performed by using Lipofectamine 2000 (Life Technologies) as per the manufacturer's protocol. All assays were conducted 48 or $72 \mathrm{~h}$ after transfection.

Cell viability assay. CellTiter-Blue cell viability assay (Promega Corporation) was performed in triplicates according to the manufacturer's protocol. Fluorescence was measured using VictorX3 Multilabel plate reader (PerkinElmer, Waltham, MA, USA) and the absolute IC50 was determined using the 4-parameter logistic model (GraphPad Software Inc., La Jolla, CA, USA) (Sebaugh, 2011). 
Cell counts. Cells were harvested and stained with 0.5\% Trypan Blue (Biochrom AG). Non-stained living cells were counted using a Neubauer chamber in triplicates.

Apoptosis assay. Caspase-Glo 3/7 assay (Promega Corporation) was performed in triplicates according to the manufacturer's protocol. Luminescence was measured using VictorX3 Multilabel plate reader (PerkinElmer) and normalised to the number of living cells.

Cell cycle analysis. Click-it EdU Alexa Fluor 488 flow cytometry assay kit (Life Technologies) was used as per the manufacturer's protocol with $10 \mathrm{um}$ EdU incorporation for $2 \mathrm{~h}$ in triplicate samples. Total DNA was stained with 7-AAD (Life Technologies). Flow cytometry was conducted on a FACSCalibur flow cytometer (BD Biosciences, San Jose, CA, USA) and analysed with FlowJo software (FlowJo LLC, Ashland, OR, USA).

Immunoblotting. Immunoblotting was performed as described previously (Nawroth et al, 2011). Antibodies against following antigens were used: Akt1, Akt2, Akt3, pAkt Thr 308, pAkt Ser 473, pan Akt, pS6K1Thr 389,S6K1, p4EBP1 Thr 37/46, p4EBP1 Ser 65, p4EBP1 Thr 70, 4EBP1, pGSK3ß Ser 9, GSK3ß, pERK 1/2 Thr 202/ Tyr 204, ERK 1/2, PI3 kinase p110alpha, pc-RAF Ser 338, pc-RAF 259, c-RAF, GAPDH, CREB (all from Cell Signaling Technology, Beverly, MA, USA), Actin (Sigma-Aldrich Chemie GmbH, Munich, Germany), DUSP1 (Santa Cruz Biotechnology, Inc., Dallas, TX, USA), and secondary antibodies were purchased from Dianova (Hamburg, Germany). Amersham ECL Prime Western blotting reagent (GE Healthcare Europe GmbH, Freiburg, Germany) was used for detection.

Chicken chorioallantoic membrane (CAM) assay. The CAM assay was performed as described previously with some modifications (Kunzi-Rapp et al, 2001). Fertilised white Leghorn chicken eggs (Brueterei Sued, Regenstauf, Germany) were incubated at $37^{\circ} \mathrm{C}$. On day 4 of incubation, the eggs were opened at the convex end. On day 9, sterilised lens paper was used to irritate a region of the CAM until bleeding was observed and a silicone ring was placed in this area. One million cells suspended in $10 \mathrm{ul}$ medium and $10 \mathrm{ul}$ phenol red free Matrigel (BD Biosciences) were incubated at $37^{\circ} \mathrm{C}$ to form a viscous mixture and then pipetted within the ring. On days 11 and 14, $500 \mathrm{~nm}$ of MK-2206 was used for topical treatment of the tumours. Concentration was calculated for the total blood volume of the developing embryo (Kind, 1975). Tumours were harvested on day 15, trimmed under a stereomicroscope (Stemi DV4, Carl Zeiss, Oberkochen, Germany) and weighed on a fine balance.

Immunohistochemistry. Immunohistochemistry was performed on 2.5 um sections from formalin-fixed, paraffin-embedded tissues with antigen retrieval by heating in $0.01 \mathrm{~m}$ citrate buffer, $\mathrm{pH}$ 6.0, blocking in 6\% hydrogen peroxide for $5 \mathrm{~min}$ and 5\% FCS-TBS for 2h. Ki-67 (Dako Deutschland GmbH, Hamburg, Germany) or pAkt Thr 308 (Bioworld Technology Inc., St Louis Park, MN, USA) antibodies were incubated for $2 \mathrm{~h}$ at room temperature. Detection was performed using the Dako REAL detection system (Dako Deutschland $\mathrm{GmbH}$ ) according to the manufacturer's protocol and sections were counterstained with haematoxylin. Images were obtained using Zen Lite 2012 software (Carl Zeiss) and analysed manually for the presence of staining in at least three fields from three independent specimens.

\section{RESULTS}

AKT isoforms contribute differentially to AKT phosphorylation and cell viability. AKT inhibitors have varying affinities towards the three AKT isoforms. Hence, we analysed the expression of
AKT isoforms and their contribution to downstream signalling in BLCA to determine prerequisites of potential AKT inhibitors. We could demonstrate expression of all three AKT isoforms in a panel of 11 different BLCA-derived cell lines (Figure 1A). As these isoforms have distinct roles in regulating cell growth (Gonzalez and McGraw, 2009), we determined their activation status in two representative cell lines by silencing their expression using two different isoform-specific siRNA oligonucleotides and analysed their expression and phosphorylation by immunoblotting (Figure 1B). The phosphorylation pattern of the individual isoforms differed in both cell lines. While only isoforms 2 and 3 were phosphorylated in 253J cells, all three isoforms were phosphorylated in HT1197 cells. When characterising the effect of AKT silencing on cell viability, each of the isoforms contributed to a decrease in cell viability. The greatest effect was seen after silencing the expression of all three isoforms (Figure 1C), indicating heterogeneous contribution of AKT isoforms to the regulation of cell growth and viability.

MK-2206 inhibits AKT/S6K1 phosphorylation and causes a cellline-dependent decrease in viability via induction of apoptosis. In order to effectively inhibit all three AKT isoforms, we used MK2206, a pan-AKT allosteric inhibitor. When treating cells with this compound, we first analysed the biochemical response of AKT downstream targets to increasing doses of MK-2206 (Figure 2A). All 11 BLCA cell lines showed a dose-dependent decrease in AKT phosphorylation in a range of $50-100 \mathrm{nM}$ corresponding to the described activity of MK-2206 (Yap et al, 2011) that was accompanied by a decrease in S6K1 phosphorylation. Although RT4 cells had no detectable phosphorylated AKT, they responded with a similar dephosphorylation of S6K1 upon MK-2206 treatment. Interestingly, none of the cell lines showed an effect on $4 \mathrm{E}-\mathrm{BP}-1$ phosphorylation of the amino acid residues $\mathrm{Thr} 37 / 46$, Ser 65 and Thr 70.

Although the biochemical data did not differ among the various cell lines, only three cell lines, 253J, HT1197 and VmCUB1, responded with a decrease of $40-60 \%$ in viability after MK-2206 treatment (Figure 2B) with an absolute IC50 of 674, 242 and $1469 \mathrm{~nm}$ respectively (Figure 2C). We confirmed this effect by directly assessing the number of living cells in six representative cell lines. 253 J, HT1197 and VmCUB1 cells showed a decrease of $37-48 \%$ after MK-2206 treatment but no such decrease was observed in $647 \mathrm{~V}, \mathrm{RT} 112$ and T24 cells (Supplementary Figure 1A).

In order to further characterise the effect of MK-2206 on cell growth, we performed apoptosis assays and cell cycle analysis in the sensitive and representative resistant cell lines. The MK-2206sensitive 253J, HT1197 and VmCUB1 cells showed an increase in caspase $3 / 7$ activity of $97 \%, 95 \%$ and $23 \%$, respectively, after treatment. No effect was apparent in the resistant $647 \mathrm{~V}$, RT112 or T24 cells (Supplementary Figure 1B). Not only all three sensitive cell lines but also the resistant T24 cells showed a modest but significant decrease in $\mathrm{S}$ phase after treatment (Supplementary Figure 1C).

DUSP1 controls ERK 1/2 phosphorylation and sensitivity to MK-2206. Apart from its regulation of mTOR signalling, AKT is an upstream component of several signalling cascades. Thus, we determined whether the biochemical basis for the differential response to MK-2206 treatment could be explained by its effects on GSK3 $\beta$, a regulator of cell proliferation (Rayasam et al, 2009), or responses in MAPK signalling that interacts at multiple levels with PI3K/AKT signalling and controls BLCA proliferation (Nawroth et al, 2011). GSK3 $\beta$ phosphorylation decreased upon AKT inhibition in six representative cell lines (Figure 3). Phosphorylation of RAF-1 at serine 338 increased after treatment, indicating activation of MAPK signalling. Serine 259 phosphorylation of RAF-1 that has been described to be negatively regulated by AKT 


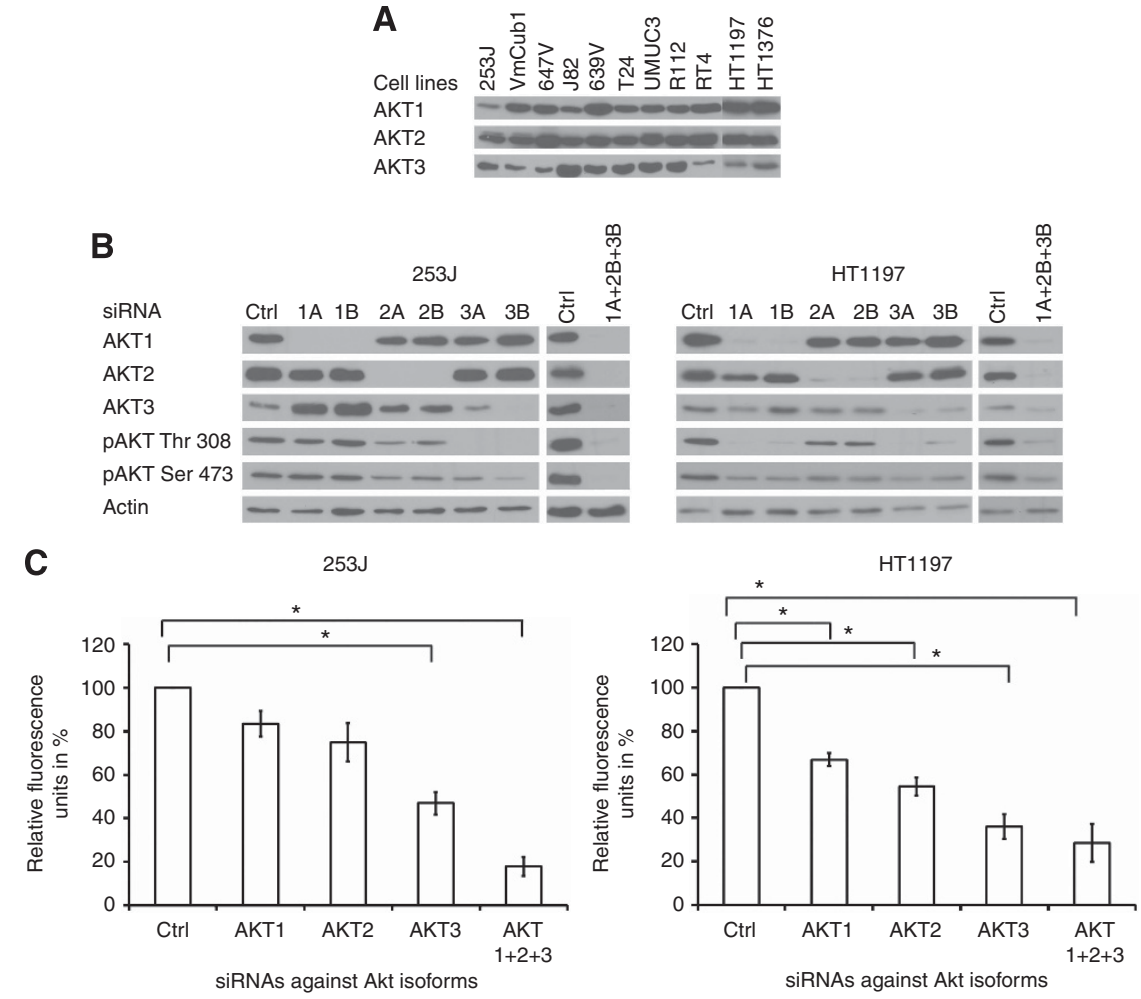

Figure 1. All three AKT isoforms are expressed in BLCA but contribute heterogeneously to active phosphorylated AKT and maintenance of cell viability. (A) Protein expression of the three AKT isoforms was analysed in a panel of cell lines by immunoblotting with the respective antibodies. (B) Representative cell lines were transfected with two different siRNA oligonucleotides against each AKT isoform (A or B) or control (ctrl), and protein expression was analysed by immunoblotting with the respective antibodies. (C) Cell viability of transfected cells was analysed at $72 \mathrm{~h}$. Values indicate mean $+/$ - s.e. expressed as percentage of control from three independent experiments. Statistical comparison was performed using the student $t$-test ( ${ }^{*}$ indicates $P<0.05$ ).

phosphorylation remained unaffected in HT1197 and VmCUB1 cells but showed an increase in 253J cells (Zimmermann, 1999). However, MK-2206-sensitive and -resistant cell lines showed opposite responses in the level of phosphorylated ERK 1/2. While the sensitive 253J, HT1197 and VmCUB1 cells showed a reduction in phosphorylated ERK $1 / 2$, the resistant $647 \mathrm{~V}, \mathrm{RT} 112$ and T24 cells showed an increase indicating that ERK 1/2 phosphorylation is regulated differently in responsive cells by a RAF-1-independent mechanism.

A potential candidate for regulating ERK 1/2 could be DUSP1 (also known as MKP-1), a phosphatase that negatively regulates ERK $1 / 2$ by dephosphorylation (Keyse, 2008). We observed an inverse relationship between DUSP1 protein expression and ERK $1 / 2$ phosphorylation in all the examined cell lines (Figure 3), with sensitive cells showing an increase and resistant cells showing a decrease in DUSP1 expression after treatment.

In order to rigorously characterise this correlation, we used siRNA oligonucleotides to suppress DUSP1 expression in all three sensitive cell lines and examined the effects on ERK phosphorylation and cell viability. MK-2206 treatment in the absence of DUSP1 failed to produce a decrease in ERK 1/2 phosphorylation in all three responsive cell lines (Figure 4A). Additionally, upon DUSP1 silencing, previously sensitive cells became resistant to MK-2206 treatment (Figure 4B). We conclude that the regulation of DUSP1 expression upon treatment and the subsequent dephosphorylation of ERK $1 / 2$ determine the responsiveness to MK-2206.

A possible link between AKT and DUSP1 regulation is CREB, an AKT downstream target and transcriptional regulator of DUSP1 (Du and Montminy, 1998; Xu et al, 2007). Thus, we suppressed the expression of CREB in HT1197 cells using siRNA oligonucleotides and treated them with MK-2206 (Supplementary Figure 2). Despite successful CREB silencing, an increase in DUSP1 expression after AKT inhibition was observed as noted previously, demonstrating that CREB does not regulate DUSP1 in these cells.

Sensitivity to MK-2206 is associated with the presence of PIK3CA mutations. Using public databases, we analysed the panel of cell lines used in this study for correlation of alterations in PTEN, PIK3CA, TSC1, RAS and FGFR3 with the response to MK-2206 in order to explain the differential sensitivity to AKT inhibition (Platt et al, 2009; Forbes et al, 2011; Lamont et al, 2011; Wellcome Trust Sanger Institute website, 2014) (Table 1). All three cell lines sensitive to MK-2206 possess activating hotspot mutations in the helical domain (HD) of the PIK3CA gene that encodes for the p110 alpha subunit of PI3K. In contrast, mutations in other PIK3CA domains, TSC1, RAS, or alterations in PTEN or FGFR3, did not correlate with sensitivity to MK-2206.

Mutant PIK3CA regulates ERK $1 / 2$ phosphorylation and sensitivity to MK-2206. In order to examine the correlation between mutations in the HD of PIK3CA and response to MK-2206 at a molecular level, we used two different strategies of genetic manipulation. First, we expressed a PIK3CA E545K mutation in $647 \mathrm{~V}, \mathrm{RT} 112$ and T24 cells that are WT for PIK3CA and examined the biochemical and functional response after MK-2206 treatment (Figure 5A). Expression of the activating mutation led to an increase in phosphorylated AKT and ERK 1/2 as compared with WT cells (comparing lane 1 and 3 ), demonstrating that the presence of mutant PIK3CA results not only in hyperphosphorylation of AKT but also in the activation of ERK signalling. After MK-2206 treatment in the presence of the PIK3CA mutation, levels of phosphorylated ERK remained 

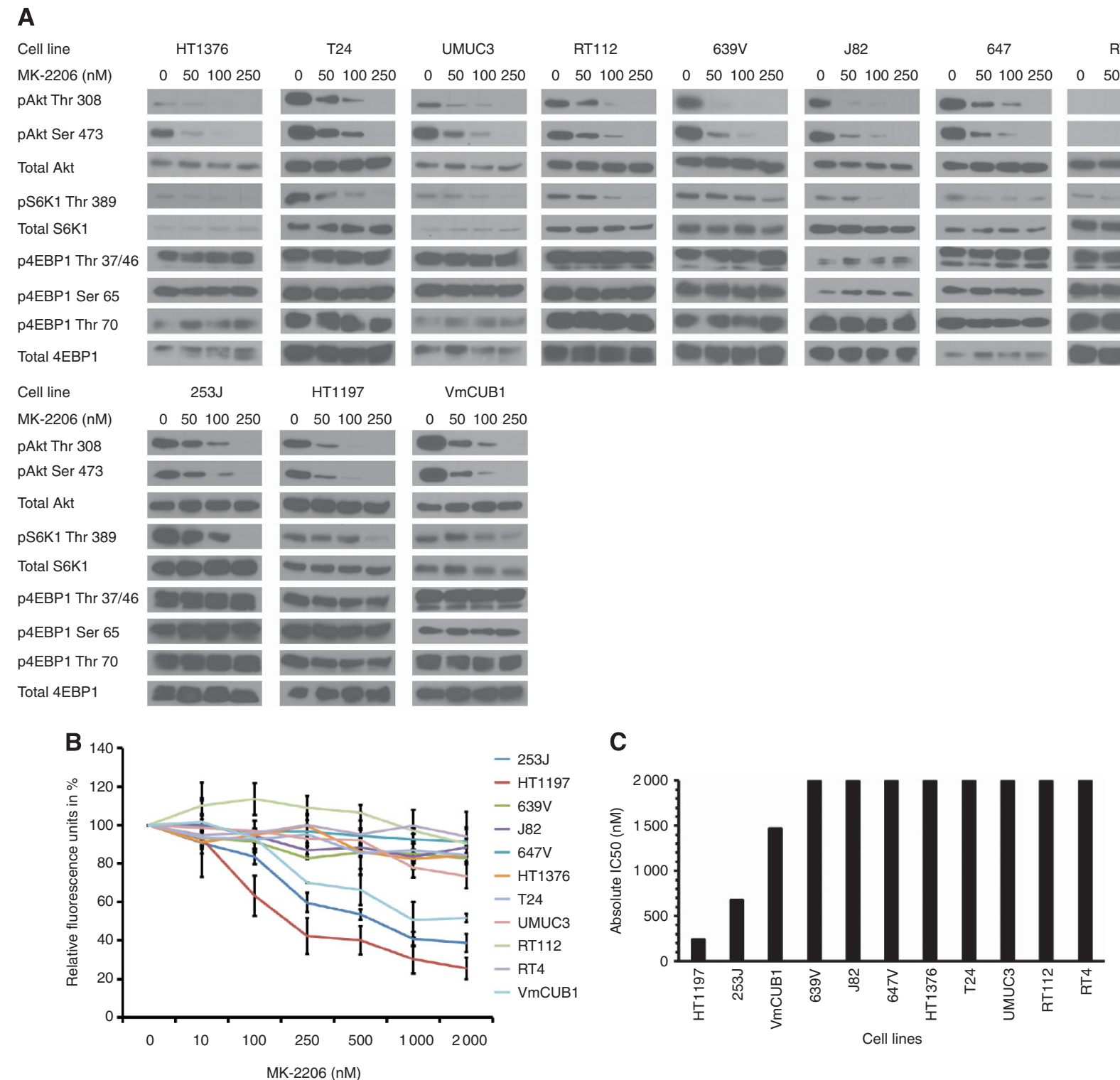

Figure 2. MK-2206 decreases AKT/mTORC1 signalling in BLCA cell lines but selectively affects BLCA viability. (A) Respective cell lines were treated for $1 \mathrm{~h}$ with indicated concentrations of MK-2206 and protein expression and phosphorylation was analysed by immunoblotting. (B) Cell viability was assessed $72 \mathrm{~h}$ after the addition of respective MK-2206 concentrations and (C) absolute inhibitory concentration (IC50) was determined. Graphs represent mean $+/$ - s.e. expressed as a percentage of control from at least three independent experiments.

unchanged in $647 \mathrm{~V}$ cells, whereas RT112 and T24 cells showed a decrease, resembling the observed biochemical response in MK-2206-sensitive PIK3CA mutant cells (as shown in Figure 3). Furthermore, the PIK3CA-transfected cells responded to MK2206 treatment with a $37-68 \%$ decrease in cell viability (Figure 5B). This was accompanied by a $30-70 \%$ decrease in cell number (Supplementary Figure 3A) and a 200-300\% increase in caspase 3/7 activity (Supplementary Figure 3B).

As a second strategy, we silenced the expression of PIK3CA in 253J and HT1197 cells with an siRNA oligonucleotide directed against the 5' untranslated region of the gene (Figure 6A). We then reconstituted them with WT PIK3CA and treated them with MK-2206 (Figure 6B). Replacement of mutant PI3KCA to WT resulted in a decrease in AKT phosphorylation and also phosphorylated ERK 1/2 (comparing lanes 1-3). Upon MK-2206 treatment, cells negative for the PIK3CA mutation no longer showed dephosphorylation of ERK 1/2. Additionally, previously sensitive cells became resistant to treatment in the absence of the mutant PIK3CA (Figure 6C).
These observations demonstrate that sensitivity to MK-2206 requires the presence of mutant $P I K 3 C A$ that regulates a biochemical response mechanism involving ERK 1/2 phosphorylation.

MK-2206 reduces proliferation of BLCA cells in a threedimensional in vivo model in the presence of mutant PIK3CA. We used a three-dimensional, in vivo xenograft model to extend our in vitro findings. The chicken CAM assay serves as an excellent substitute for animal experiments (Flecknell, 2002) and represents an in vivo immunodeficient model where cells can form three-dimensional tumours with a complex vascular network (Kunzi-Rapp et al, 2001). We generated tumour xenografts of the representative cell lines HT1197 and RT112 on the developing CAM (Supplementary Figure 4A). Tumours were treated with MK-2206 and analysed for weight, AKT phosphorylation and proliferation as determined by Ki-67 expression. Upon treatment, tumour weights were significantly reduced by about $50 \%$ in HT1197 cells, whereas RT112 tumours showed no such decrease (Figure 7A). MK-2206 induced a decrease in AKT phosphorylation 


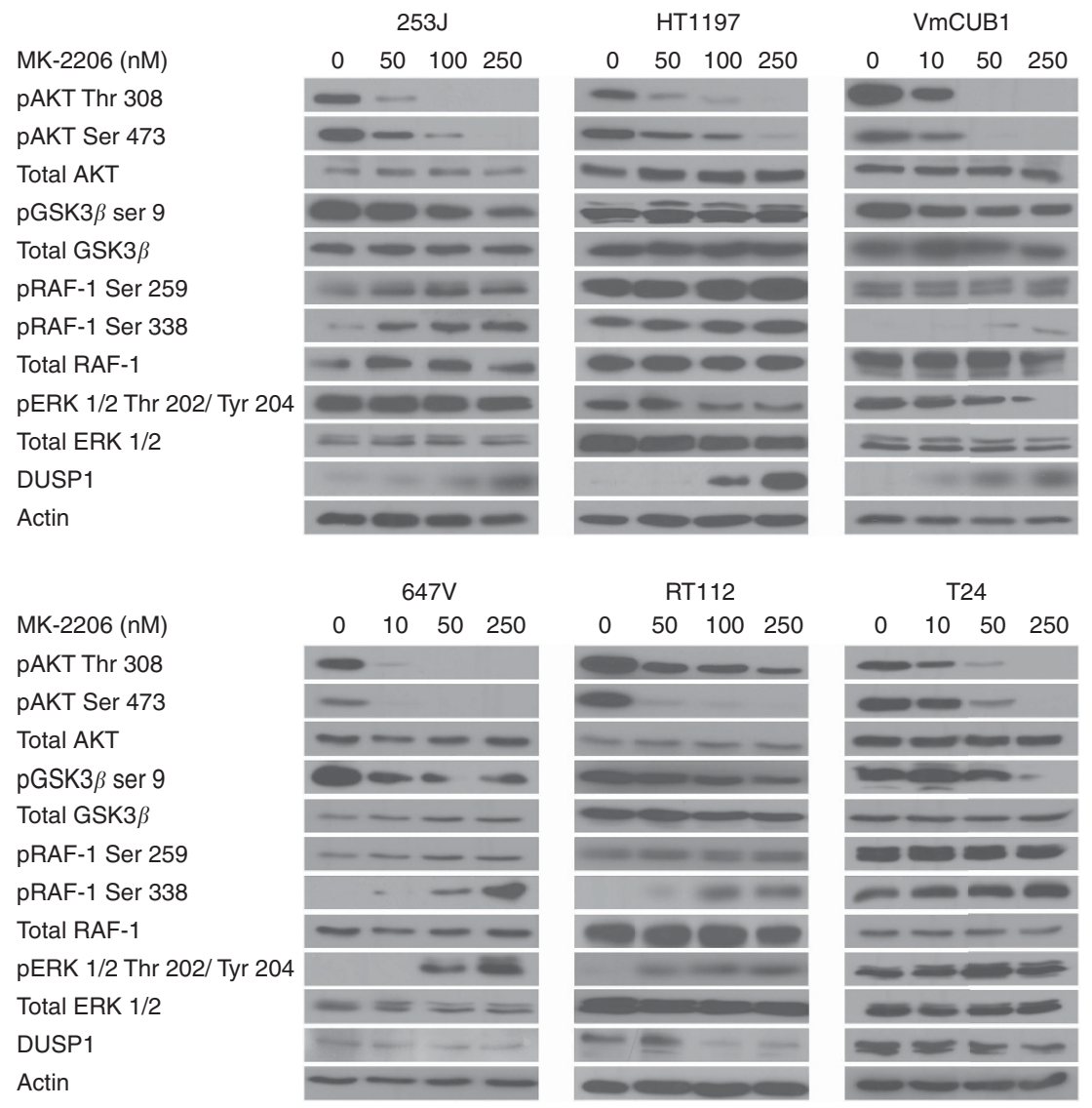

Figure 3. MK-2206-sensitive cells show a reduction in ERK 1/2 phosphorylation and an increase in DUSP1 expression after treatment. Cell lines were incubated with indicated MK-2206 concentrations for $1 \mathrm{~h}$ and protein expression and phosphorylation pattern was analysed by immunoblotting.

A

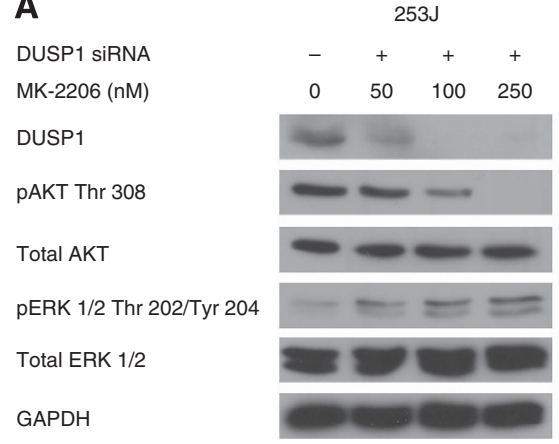

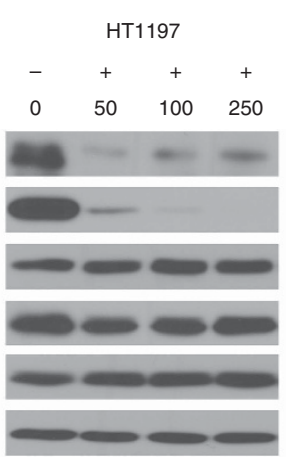
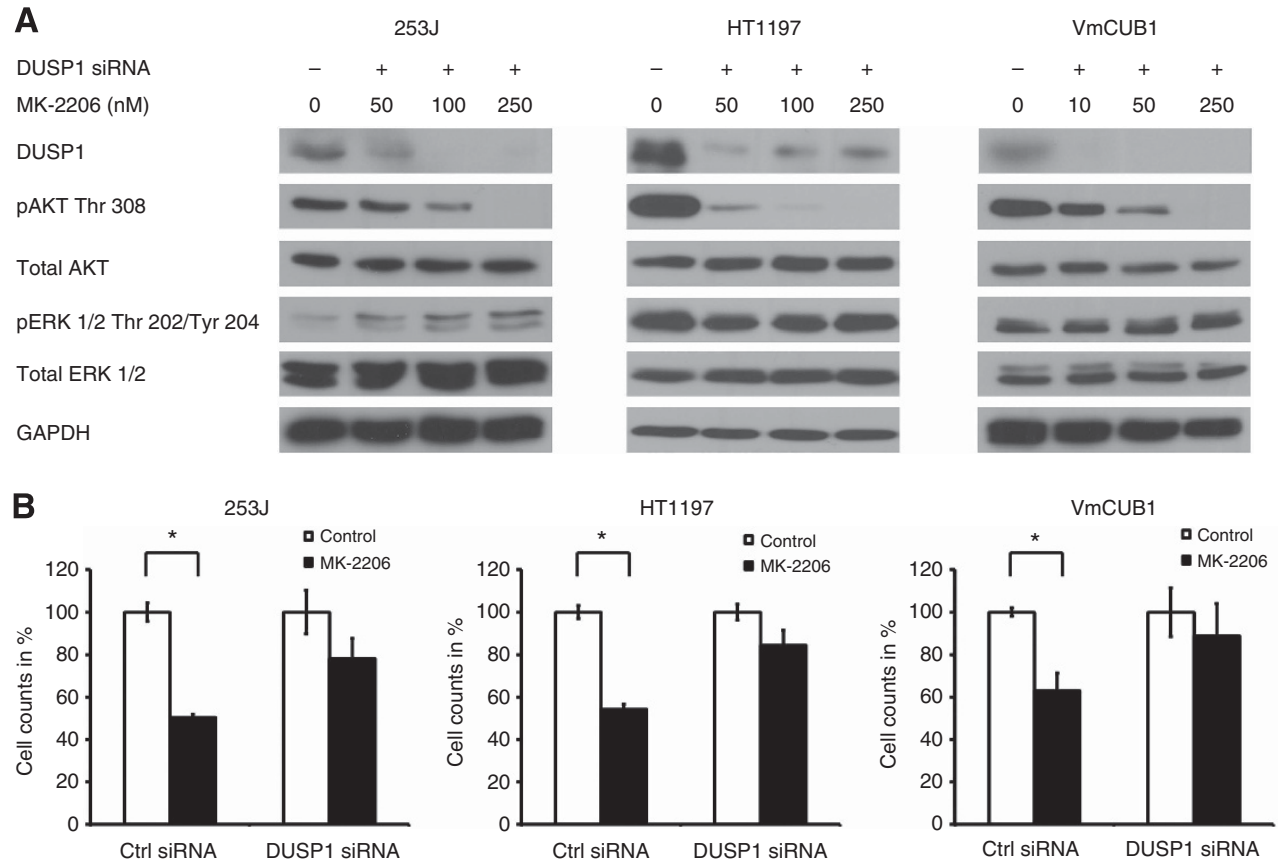

Figure 4. DUSP1-mediated regulation of ERK $1 / 2$ phosphorylation regulates sensitivity to MK-2206. (A) Cells transfected with control (ctrl) or DUSP1-directed siRNA oligonucleotides were treated with indicated concentrations of MK-2206 for $1 \mathrm{~h}$ in the respective cell lines. ' $+{ }^{\prime}$ indicates present and ' $-{ }^{\prime}$ indicates absent. (B) Transfected cells were treated with $1000 \mathrm{~nm}$ of MK-2206 for a further $72 \mathrm{~h}$ and the number of viable cells was assessed. Graphs indicate mean viable cell counts $+/$ - s.e. expressed as a percentage of control and represent at least three independent experiments. Statistical comparison was performed using the student $t$-test ( ${ }^{*}$ indicates $P<0.05$ ). 
Table 1. Genetic background of cell lines and their response to MK-2206

\begin{tabular}{|c|c|c|c|c|c|c|}
\hline Cell line & PIKЗСA & PTEN status & TSC1 & RAS & $\begin{array}{l}\text { FGFR3 status/ } \\
\text { expression }\end{array}$ & $\begin{array}{l}\text { Response to } \\
\text { MK2206 }\end{array}$ \\
\hline RT112 & WT & WT & WT & WT & WT overexpressed & Resistant \\
\hline RT4 & WT & $\begin{array}{l}\text { WT, reduced } \\
\text { copy number }\end{array}$ & Mutant & WT & WT overexpressed & Resistant \\
\hline $647 \mathrm{~V}$ & WT & $\begin{array}{l}\text { WT, reduced } \\
\text { copy number }\end{array}$ & WT & WT & WT & Resistant \\
\hline HT1376 & WT & WT & WT & WT & WT & Resistant \\
\hline T24 & WT & Mutant & WT & $\begin{array}{l}\text { HRAS Mutant, KRAS WT, } \\
\text { NRAS WT }\end{array}$ & WT & Resistant \\
\hline UMUC3 & WT & $\begin{array}{l}\text { Homozygous } \\
\text { deletion }\end{array}$ & WT & $\begin{array}{l}\text { KRAS Mutant, NRAS WT, } \\
\text { HRAS WT }\end{array}$ & WT & Resistant \\
\hline J82 & P124L rare mutant & $\begin{array}{l}\text { Homozygous } \\
\text { deletion }\end{array}$ & WT & WT & Mutant & Resistant \\
\hline $639 \mathrm{~V}$ & A1066V rare mutant & Mutant & Mutant & $\begin{array}{l}\text { KRAS Mutant, NRAS } \\
\text { Mutant, HRAS WT }\end{array}$ & WT & Resistant \\
\hline $253 \mathrm{~J}$ & E545G hotspot helical domain mutant & WT & WT & WT & WT & Sensitive \\
\hline HT1197 & E545K hotspot helical domain mutant & $\begin{array}{l}\text { WT, reduced } \\
\text { copy number }\end{array}$ & WT & $\begin{array}{l}\text { NRAS Mutant, HRAS WT, } \\
\text { KRAS WT }\end{array}$ & WT & Sensitive \\
\hline VM-CUB1 & $\begin{array}{l}\text { E542K hotspot helical domain and E6740 } \\
\text { helical domain mutant }\end{array}$ & WT & WT & WT & WT & Sensitive \\
\hline
\end{tabular}

A

\begin{tabular}{|c|c|}
\hline $\mathbf{A}$ & $\begin{array}{cc} & 647 \mathrm{~V} \\
& \text { PIK3CA } \\
\text { Ctrl } \quad \text { E545K }\end{array}$ \\
\hline MK-2206 (nM) & 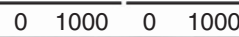 \\
\hline 110 alpha & \\
\hline pAkt Thr 308 & - \\
\hline pAkt Ser 473 & 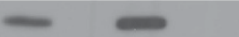 \\
\hline Total Akt & $=0$ \\
\hline Erk 1/2 Thr 202/Tyr 204 & $==$ \\
\hline otal Erk 1/2 & $==$ \\
\hline & \\
\hline
\end{tabular}

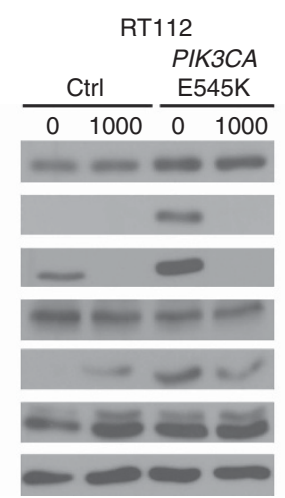

RT112

B
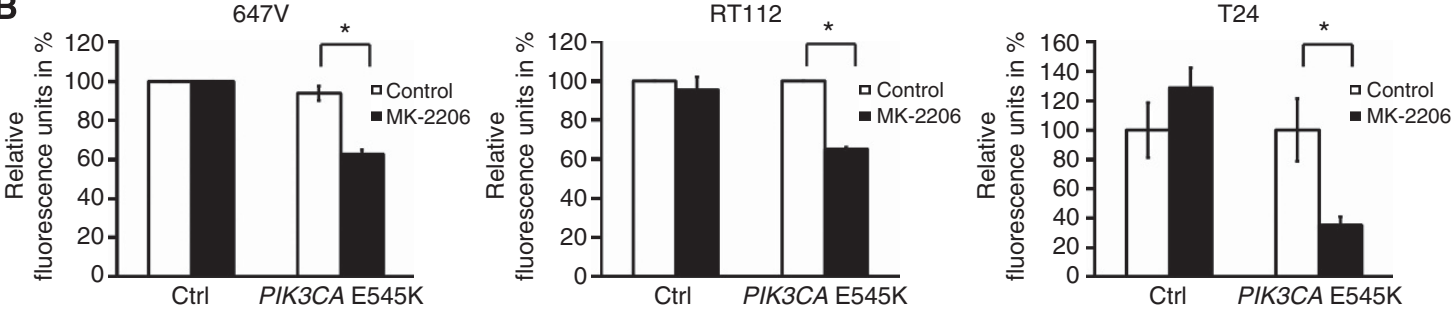

Figure 5. Resistant cells are sensitive to MK-2206 in the presence of mutant PIK3CA and show a decrease in ERK 1/2 phosphorylation.

(A) Cells transfected with either control vector (ctrl) or mutant PIK3CA E545K were treated for $1 \mathrm{~h}$ with $1000 \mathrm{~nm}$ MK-2206 for immunoblotting.

(B) Transfected cells were treated for a further $72 \mathrm{~h}$ to assess cell viability. Graphs indicate mean $+/-$ s.e. expressed as a percentage of control and are representative of at least three independent experiments. Statistical comparison was performed using the student $t$-test $\left(^{*}\right.$ indicates $P<0.05$ ).

of around $50-70 \%$ in both and a reduction of Ki-67 expression by $54 \%$ in HT1197 tumours, with no significant change in RT112 tumours (Figure 7B, Supplementary Figure 4B). We then grafted RT112 cells transfected with a control vector or with PIK3CA E545K and treated the tumours with MK-2206. While tumours containing the control vector did not respond to MK-2206, cells expressing the mutant PIK3CA showed a 56\% decrease in weight after treatment (Figure 7C). While MK-2206 induced a decrease in AKT phosphorylation of around $80 \%$ in both, Ki-67 expression was significantly reduced by $55 \%$ only in cells containing PIK3CA E545K (Supplementary Figure 4C).

\section{DISCUSSION}

In this study, we describe a molecular mechanism that regulates the response to AKT therapy in BLCA.

We first demonstrated in a panel of 11 cell lines with characterised genomic alterations that all AKT isoforms are expressed and that they contribute heterogeneously to active phosphorylated AKT. Although diverse roles of these isoforms have been described in cell cycle regulation and cell migration (Gonzalez and McGraw, 2009), their functional role in BLCA has 
A

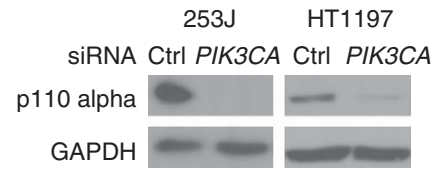

B
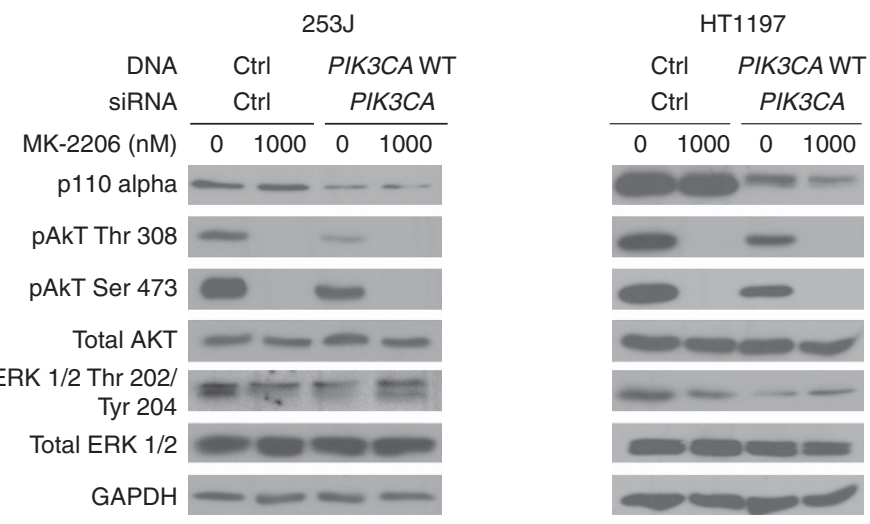

C

253J

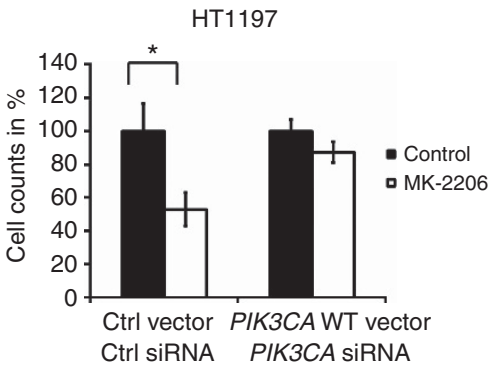

Figure 6. Sensitive cells become resistant to MK-2206 upon loss of mutant PIK3CA and show an increase in ERK 1/2 phosphorylation. (A) Cells were transfected with control (ctrl) or siRNA oligonucleotides against PIK3CA. (B) siRNA-transfected cells were then transfected with control (ctrl) or WT PIK3CA containing vector and treated with $1000 \mathrm{~nm}$ MK-2206 for $1 \mathrm{~h}$ for immunoblotting or (C) incubated for another $72 \mathrm{~h}$ to assess cell viability. Graphs indicate mean viable cell counts $+/-$ s.e. expressed as a percentage of control and represent at least three independent experiments. Statistical comparison was performed using the student $t$-test ( ${ }^{*}$ indicates $P<0.05$ ).

not been previously examined. AKT inhibitors differ in their affinity towards AKT isoforms and several selectively target only AKT1 and AKT2 (Mattmann et al, 2011). Our results demonstrate that inhibitors used in BLCA should target all three AKT isoforms.

For characterising the therapeutic effect of AKT target therapy in BLCA, we examined the biochemical and functional response of cell lines to the pan-AKT inhibitor MK-2206. Upon treatment with MK-2206, decreased phosphorylation of AKT and its downstream mTOR substrate S6K1 could be observed. No dephosphorylation was observed in different amino acid residues of 4E-BP1, a second important downstream target of mTORC1. We have previously shown that rapalogues (RAD001, CCI-779) or shRNA-mediated silencing of mTOR affects only the phosphorylation of S6K1 and not 4E-BP1 in BLCA. However, dual PI3K inhibitors such as NVPBEZ235 did result in dephosphorylation of both S6K1 and 4E-BP1 (Nawroth et al, 2011). These data extend our previous results that $4 \mathrm{E}-\mathrm{BP} 1$ phosphorylation is not regulated by the AKT/mTOR axis of the pathway but that there might be another link between PI3K inhibition and 4E-BP1 regulation that has not been revealed to date. Interestingly, the same response was observed in RT4 cells that had no detectable AKT phosphorylation. This might indicate that either MK-2206 is not as specific as described or that RT4 cells possess phosphorylation levels that are non-detectable by western blotting but are sufficient to regulate further downstream signalling events.

On a functional level, despite successful downregulation of AKT phosphorylation, MK-2206 treatment inhibited cell viability only in cell lines possessing mutations in the HD of PIK3CA that result in constitutive activation of PI3K. Mutations found in non-hotspot regions of the $\mathrm{HD}$ result in $\mathrm{AKT}$ activation to a lesser degree (Ross et al, 2013) and were not associated with sensitivity to MK-2206 in our panel of cell lines (Table 1). Bladder cancer possesses a different spectrum of PIK3CA mutations compared with other tumour entities, with about $80 \%$ occurring in hotspot regions of the HD (Platt et al, 2009). Around 15-20\% of BLCA patients are predicted to bear these mutations (Platt et al, 2009; Cancer Genome Atlas Research Network, 2014) and thus have the potential to benefit from AKT target therapy.

Representative sensitive and resistant cell lines showed a modest decrease in cell cycle progression after MK-2206 treatment, as described previously for breast cancer and T-cell leukaemia (She et al, 2008; Sangai et al, 2012; Simioni et al, 2012). Only sensitive cells demonstrated an increase in caspase 3/7 activity suggesting that the response to MK-2206-induced inhibition of tumour growth is mediated by an increase in apoptosis.

The association between sensitivity to AKT inhibition and specific PIK3CA mutations has also been observed in thyroid and breast cancer. However, in these studies, sensitivity also correlated with PTEN and in thyroid cancer also with RAS mutations (Liu et al, 2011; Sangai et al, 2012). No correlations with PIK3CA, PTEN or RAS mutations and AKT target therapy have been observed in non-small cell lung cancer (Meng et al, 2010). This suggests that the predictive character of the genetic determinants of drug sensitivity differs between tumour entities. Also in our study, cell lines displaying similar alterations in PTEN or RAS were not responsive.

An ATP-competitive AKT inhibitor, AZ7328, has been tested on a panel of BLCA-derived cell lines before (Dickstein et al, 2012). In this study, no clear predictable pattern of associations between 

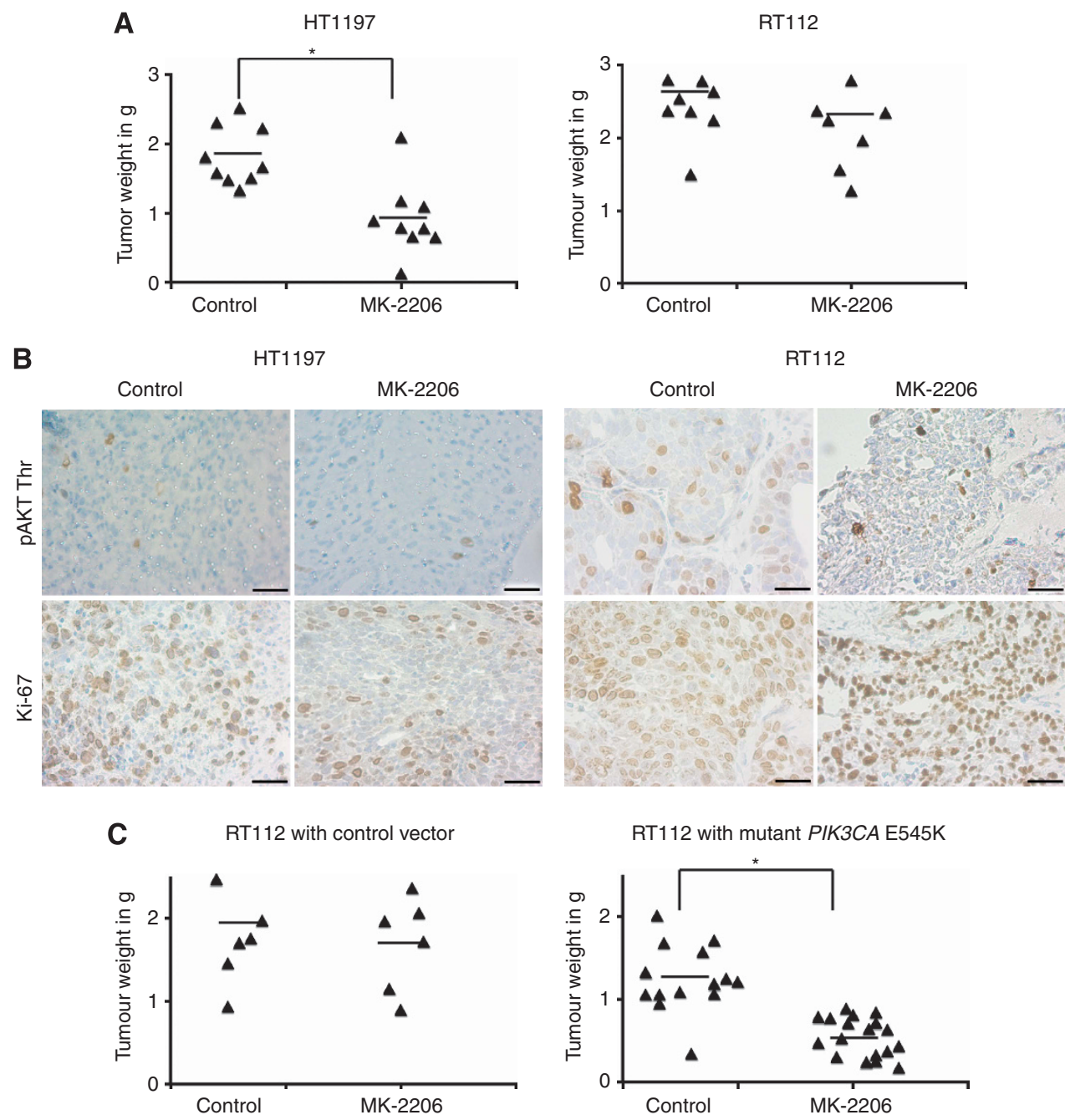

Figure 7. HD mutant PIK3CA confers sensitivity to MK-2206 in vivo. (A) Tumours from indicated cell lines were harvested and weighed after MK-2206 or control treatment. (B) Representative images from tumours, which were analysed with IHC using the indicated antibodies. Scale bar $=20 \mu \mathrm{M}$. (C) RT112 tumours transfected with either control vector or mutant PIK3CA E545K were harvested after control or MK-2206 treatment and weighed. For all graphs, each dot indicates a data point and line indicates the mean. Statistical comparison was performed using the student t-test ${ }^{*}$ indicates $\left.P<0.05\right)$. All results are representative of at least two independent experiments.

the presence of alterations in PIK3CA and the sensitivity to AKT inhibition was observed, although cells possessing mutant PIK3CA did respond with a lower IC50 for growth inhibition. This suggests, that the mode of action of different inhibitors used might largely influence therapy response (Dickstein et al, 2012; Haibe-Kains et al, 2013). MK-2206 was also previously examined in a panel of BLCA cell lines. Mutations in PIK3CA or AKT1 correlated with sensitivity to the drug, whereas PTEN and TSC1 alterations did not (Iyer et al, 2013). However, the authors did not provide a direct molecular characterisation of specific mutations and therapy response. We have extended these data to provide a mechanistic explanation by rigorously examining the contribution of a single mutation in PIK3CA to drug sensitivity. Our results clearly demonstrate that the presence of only a PIK3CA mutation is sufficient to confer sensitivity to MK-2206 both in vitro and in vivo.

Upon treatment with MK-2206, activation of the MAPK signalling pathway by an increase in Raf-1 phosphorylation was observed in both WT and mutant PIK3CA expressing cells. This observation is in agreement with studies that have demonstrated an upregulation of tyrosine kinases after AKT inhibition via feedback loops (Chandarlapaty et al, 2011; Cen et al, 2013). Also, introduction of the mutant PIK3CA E545K resulted in an increase in ERK phosphorylation confirming a recent study that demonstrated crosstalk between PI3K and MAPK signalling (Will et al, 2014). However, we show here that expression of PIK3CA E545K has a regulatory role in DUSP1 expression. Inhibition of AKT in this situation results in a downregulation of ERK $1 / 2$ and subsequently induces apoptosis. This represents a biochemical signature of response and has not been described previously. The reduction in ERK $1 / 2$ activity promotes apoptosis and decreases tumour growth, which is in line with reports that this decrease after PI3K inhibition is essential to initiate apoptosis and sensitise cells to the inhibitor (Will et al, 2014).

It remains to be examined whether AKT inhibition in the presence of mutant PIK3CA influences DUSP1 expression due to hyperactivation of the PI3K or MAPK signalling pathway or due to other properties of the mutant such as protein complex formation. We have verified that this mechanism is not regulated via CREB, which has been described as an AKT substrate (Du and Montminy, 1998). DUSP1 is expressed at higher levels in early stages of bladder carcinogenesis (Loda et al, 1996). Given its impact on the regulation of cell proliferation and response to treatment, it warrants further investigation as a potential therapeutic target in BLCA.

The interplay between mutant PIK3CA, DUSP1, ERK phosphorylation and AKT inhibition demonstrates the complexity in cell signalling involving a non-linear signalling cascade and 
crosstalk between the PI3K and MAPK pathways, which ultimately influences therapy response. These interactions make it likely that the application of AKT target therapy will have a complicated transition to the clinic. We demonstrate that this therapy is likely to benefit a subset of patients whose tumour genetics determine the responsiveness to therapy. In BLCA, a disease for which target therapy is still in early stages of development, our data suggest that AKT therapy can benefit patients possessing hotspot HD PIK3CA mutations. In addition, this mutation might be used as a stratifying biomarker to personalise treatment in patients with advanced BLCA.

\section{ACKNOWLEDGEMENTS}

We are grateful to Ms F Genze (University of Ulm, Ulm, Germany) for technical assistance in the establishment of the CAM assay.

\section{CONFLICT OF INTEREST}

The authors declare no conflict of interest.

\section{AUTHOR CONTRIBUTIONS}

AS and RN conceived and designed the study. AS, FG, MVC and RN developed the methodology. AS and FG acquired the data. AS and RN analysed and interpreted it. The manuscript was written and reviewed by AS, JEG, MR and RN; administrative and material support was provided by MMH and MT.

\section{REFERENCES}

Bellmunt J, Fougeray R, Rosenberg JE, von der Maase H, Schutz FA, Salhi Y, Culine S, Choueiri TK (2013) Long-term survival results of a randomized phase III trial of vinflunine plus best supportive care versus best supportive care alone in advanced urothelial carcinoma patients after failure of platinum-based chemotherapy. Ann Oncol 24(6): 1466-1472.

Cancer Genome Atlas Research Network (2014) Comprehensive molecular characterization of urothelial bladder carcinoma. Nature 507(7492): 315-322.

Cen B, Mahajan S, Wang W, Kraft AS (2013) Elevation of receptor tyrosine kinases by small molecule AKT inhibitors in prostate cancer is mediated by Pim-1. Cancer Res 73(11): 3402-3411.

Chandarlapaty S, Sawai A, Scaltriti M, Rodrik-Outmezguine V, Grbovic-Huezo O, Serra V, Majumder PK, Baselga J, Rosen N (2011) AKT inhibition relieves feedback suppression of receptor tyrosine kinase expression and activity. Cancer Cell 19(1): 58-71.

Ciriello G, Miller ML, Aksoy BA, Senbabaoglu Y, Schultz N, Sander C (2013) Emerging landscape of oncogenic signatures across human cancers. Nat Genet 45(10): 1127-1133.

Dickstein RJ, Nitti G, Dinney CP, Davies BR, Kamat AM, McConkey DJ (2012) Autophagy limits the cytotoxic effects of the AKT inhibitor AZ7328 in human bladder cancer cells. Cancer Biol Ther 13(13): $1325-1338$

Du K, Montminy M (1998) CREB is a regulatory target for the protein kinase Akt/PKB. J Biol Chem 273(49): 32377-32379.

Flecknell P (2002) Replacement, reduction and refinement. ALTEX 19(2): 73-78.

Forbes SA, Bindal N, Bamford S, Cole C, Kok CY, Beare D, Jia M, Shepherd R, Leung K, Menzies A, Teague JW, Campbell PJ, Stratton MR, Futreal PA (2011) COSMIC: mining complete cancer genomes in the Catalogue of Somatic Mutations in Cancer. Nucleic Acids Res 39(Database issue): D945-D950.

Gerullis H, Ecke TH, Janusch B, Arndt C, Heidari M, Oniani J, Otto T (2011) Long-term response in advanced bladder cancer involving the use of temsirolimus and vinflunine after platin resistance. Anticancer Drugs 22(9): 940-943.
Gonzalez E, McGraw TE (2009) The Akt kinases: isoform specificity in metabolism and cancer. Cell Cycle 8(16): 2502-2508.

Haibe-Kains B, El-Hachem N, Birkbak NJ, Jin AC, Beck AH, Aerts HJ, Quackenbush J (2013) Inconsistency in large pharmacogenomic studies. Nature 504(7480): 389-393.

Iyer G, Al-Ahmadie H, Schultz N, Hanrahan AJ, Ostrovnaya I, Balar AV, Kim PH, Lin O, Weinhold N, Sander C, Zabor EC, Janakiraman M, Garcia-Grossman IR, Heguy A, Viale A, Bochner BH, Reuter VE, Bajorin DF, Milowsky MI, Taylor BS, Solit DB (2013) Prevalence and co-occurrence of actionable genomic alterations in high-grade bladder cancer. J Clin Oncol 31(25): 3133-3140.

Iyer G, Hanrahan AJ, Milowsky MI, Al-Ahmadie H, Scott SN, Janakiraman M, Pirun M, Sander C, Socci ND, Ostrovnaya I, Viale A, Heguy A, Peng L, Chan TA, Bochner B, Bajorin DF, Berger MF, Taylor BS, Solit DB (2012) Genome sequencing identifies a basis for everolimus sensitivity. Science 338(6104): 221.

Keyse SM (2008) Dual-specificity MAP kinase phosphatases (MKPs) and cancer. Cancer Metastasis Rev 27(2): 253-261.

Kind C (1975) The development of the circulating blood volume of the chick embryo. Anat Embryol 147(2): 127-132.

Klempner SJ, Myers AP, Cantley LC (2013) What a tangled web we weave: emerging resistance mechanisms to inhibition of the phosphoinositide 3-kinase pathway. Cancer Discov 3(12): 1345-1354.

Knowles MA, Platt FM, Ross RL, Hurst CD (2009) Phosphatidylinositol 3-kinase (PI3K) pathway activation in bladder cancer. Cancer Metastasis Rev 28(3-4): 305-316.

Kunzi-Rapp K, Genze F, Kufer R, Reich E, Hautmann RE, Gschwend JE (2001) Chorioallantoic membrane assay: vascularized 3-dimensional cell culture system for human prostate cancer cells as an animal substitute model. J Urol 166(4): 1502-1507.

Lamont FR, Tomlinson DC, Cooper PA, Shnyder SD, Chester JD, Knowles MA (2011) Small molecule FGF receptor inhibitors block FGFR-dependent urothelial carcinoma growth in vitro and in vivo. Br J Cancer 104(1): 75-82.

Liu R, Liu D, Trink E, Bojdani E, Ning G, Xing M (2011) The Akt-specific inhibitor MK2206 selectively inhibits thyroid cancer cells harboring mutations that can activate the PI3K/Akt pathway. J Clin Endocrinol Metab 96(4): E577-E585.

Loda M, Capodieci P, Mishra R, Yao H, Corless C, Grigioni W, Wang Y, Magi-Galluzzi C, Stork PJ (1996) Expression of mitogen-activated protein kinase phosphatase- 1 in the early phases of human epithelial carcinogenesis. Am J Pathol 149(5): 1553-1564.

Manning BD, Cantley LC (2007) AKT/PKB signaling: navigating downstream. Cell 129(7): 1261-1274.

Mattmann ME, Stoops SL, Lindsley CW (2011) Inhibition of Akt with small molecules and biologics: historical perspective and current status of the patent landscape. Exp Opin Ther Pat 21(9): 1309-1338.

Meng J, Dai B, Fang B, Bekele BN, Bornmann WG, Sun D, Peng Z, Herbst RS, Papadimitrakopoulou V, Minna JD, Peyton M, Roth JA (2010) Combination treatment with MEK and AKT inhibitors is more effective than each drug alone in human non-small cell lung cancer in vitro and in vivo. PLoS One 5(11): e14124.

Milowsky MI, Iyer G, Regazzi AM, Al-Ahmadie H, Gerst SR, Ostrovnaya I, Gellert LL, Kaplan R, Garcia-Grossman IR, Pendse D, Balar AV, Flaherty AM, Trout A, Solit DB, Bajorin DF (2013) Phase II study of everolimus in metastatic urothelial cancer. BJU Int 112(4): 462-470.

Nawroth R, Stellwagen F, Schulz WA, Stoehr R, Hartmann A, Krause BJ, Gschwend JE, Retz M (2011) S6K1 and 4E-BP1 are independent regulated and control cellular growth in bladder cancer. PLoS One 6(11): e27509.

O'Reilly KE, Rojo F, She QB, Solit D, Mills GB, Smith D, Lane H, Hofmann F, Hicklin DJ, Ludwig DL, Baselga J, Rosen N (2006) mTOR inhibition induces upstream receptor tyrosine kinase signaling and activates Akt. Cancer Res 66(3): 1500-1508.

Platt FM, Hurst CD, Taylor CF, Gregory WM, Harnden P, Knowles MA (2009) Spectrum of phosphatidylinositol 3-kinase pathway gene alterations in bladder cancer. Clin Cancer Res 15(19): 6008-6017.

Rayasam GV, Tulasi VK, Sodhi R, Davis JA, Ray A (2009) Glycogen synthase kinase 3: more than a namesake. Br J Pharmacol 156(6): 885-898.

Rodon J, Dienstmann R, Serra V, Tabernero J (2013) Development of PI3K inhibitors: lessons learned from early clinical trials. Nat Rev Clin Oncol 10(3): 143-153. 
Ross RL, Askham JM, Knowles MA (2013) PIK3CA mutation spectrum in urothelial carcinoma reflects cell context-dependent signaling and phenotypic outputs. Oncogene 32(6): 768-776.

Samuels Y, Wang Z, Bardelli A, Silliman N, Ptak J, Szabo S, Yan H, Gazdar A, Powell SM, Riggins GJ, Willson JK, Markowitz S, Kinzler KW, Vogelstein B, Velculescu VE (2004) High frequency of mutations of the PIK3CA gene in human cancers. Science 304(5670): 554.

Sangai T, Akcakanat A, Chen H, Tarco E, Wu Y, Do KA, Miller TW, Arteaga CL, Mills GB, Gonzalez-Angulo AM, Meric-Bernstam F (2012) Biomarkers of response to Akt inhibitor MK-2206 in breast cancer. Clin Cancer Res 18(20): 5816-5828.

Sebaugh JL (2011) Guidelines for accurate EC50/IC50 estimation. Pharm Stat 10(2): 128-134.

Seront E, Rottey S, Sautois B, Kerger J, D'Hondt LA, Verschaeve V, Canon JL, Dopchie C, Vandenbulcke JM, Whenham N, Goeminne JC, Clausse M, Verhoeven D, Glorieux P, Branders S, Dupont P, Schoonjans J, Feron O, Machiels JP (2012) Phase II study of everolimus in patients with locally advanced or metastatic transitional cell carcinoma of the urothelial tract: clinical activity, molecular response, and biomarkers. Ann Oncol 23(10): 2663-2670.

She QB, Chandarlapaty S, Ye Q, Lobo J, Haskell KM, Leander KR, DeFeo-Jones D, Huber HE, Rosen N (2008) Breast tumor cells with PI3K mutation or HER2 amplification are selectively addicted to Akt signaling. PLoS One 3(8): e3065.

Simioni C, Neri LM, Tabellini G, Ricci F, Bressanin D, Chiarini F, Evangelisti C, Cani A, Tazzari PL, Melchionda F, Pagliaro P, Pession A, McCubrey JA, Capitani S, Martelli AM (2012) Cytotoxic activity of the novel Akt inhibitor, MK-2206, in T-cell acute lymphoblastic leukemia. Leukemia 26(11): 2336-2342.

Sun SY, Rosenberg LM, Wang X, Zhou Z, Yue P, Fu H, Khuri FR (2005) Activation of Akt and eIF4E survival pathways by rapamycin-mediated mammalian target of rapamycin inhibition. Cancer Res 65(16): 7052-7058.

U.S. National Library of Medicine Clinical Trials (2014a) U.S. National Library of Medicine: Bethesda, MD, USA. http://clinicaltrials.gov (accessed 25 September 2014).

U.S. National Library of Medicine Clinical Trials (2014b) U.S. National Library of Medicine: Bethesda, MD, USA. http://clinicaltrials.gov/ct2/ results?term=NCT01186705 (accessed 25 September 2014).

U.S. National Library of Medicine Clinical Trials (2014c) U.S. National Library of Medicine: Bethesda, MD, USA. http://clinicaltrials.gov/ct2/ results?term=NCT01306045 (accessed 25 September 2014).

U.S. National Library of Medicine Clinical Trials (2014d) U.S. National Library of Medicine: Bethesda, MD, USA. http://clinicaltrials.gov/ct2/ results?term=NCT01312753 (accessed 25 September 2014).

U.S. National Library of Medicine Clinical Trials (2014e) U.S. National Library of Medicine: Bethesda, MD, USA. http://clinicaltrials.gov/ct2/ results?term=NCT01277757 (accessed 25 September 2014). von der Maase H, Hansen SW, Roberts JT, Dogliotti L, Oliver T, Moore MJ, Bodrogi I, Albers P, Knuth A, Lippert CM, Kerbrat P, Sanchez Rovira P, Wersall P, Cleall SP, Roychowdhury DF, Tomlin I, Visseren-Grul CM, Conte PF (2000) Gemcitabine and cisplatin versus methotrexate, vinblastine, doxorubicin, and cisplatin in advanced or metastatic bladder cancer: results of a large, randomized, multinational, multicenter, phase III study. J Clin Oncol 18(17): 3068-3077.

Weigelt B, Downward J (2012) Genomic determinants of PI3K pathway inhibitor response in cancer. Front Oncol 2: 109.

Wellcome Trust Sanger Institute website (2014) Wellcome Trust Sanger Institute: Hinxton, UK. http://cancer.sanger.ac.uk/cancergenome/projects/ cell_lines (accessed 25 September 2014).

Will M, Qin AC, Toy W, Yao Z, Rodrik-Outmezguine V, Schneider C, Huang X, Monian P, Jiang X, de Stanchina E, Baselga J, Liu N, Chandarlapaty S, Rosen N (2014) Rapid induction of apoptosis by PI3K inhibitors is dependent upon their transient inhibition of RAS-ERK signaling. Cancer Discov 4(3): 334-347.

Witjes JA, Comperat E, Cowan NC, De Santis M, Gakis G, Lebret T, Ribal MJ, Van der Heijden AG, Sherif A (2013) EAU guidelines on muscle-invasive and metastatic bladder cancer: summary of the 2013 guidelines. Eur Urol 65: 778-792.

Xu W, Kasper LH, Lerach S, Jeevan T, Brindle PK (2007) Individual CREB-target genes dictate usage of distinct cAMP-responsive coactivation mechanisms. EMBO J 26(12): 2890-2903.

Yap TA, Yan L, Patnaik A, Fearen I, Olmos D, Papadopoulos K, Baird RD, Delgado L, Taylor A, Lupinacci L, Riisnaes R, Pope LL, Heaton SP, Thomas G, Garrett MD, Sullivan DM, de Bono JS, Tolcher AW (2011) First-in-man clinical trial of the oral pan-AKT inhibitor MK-2206 in patients with advanced solid tumors. J Clin Oncol 29(35): 4688-4695.

Yuan TL, Cantley LC (2008) PI3K pathway alterations in cancer: variations on a theme. Oncogene 27(41): 5497-5510.

Zhao JJ, Liu Z, Wang L, Shin E, Loda MF, Roberts TM (2005) The oncogenic properties of mutant p110alpha and p110beta phosphatidylinositol 3-kinases in human mammary epithelial cells. Proc Natl Acad Sci USA 102(51): 18443-18448.

Zimmermann S (1999) Phosphorylation and regulation of Raf by Akt (protein kinase B). Science 286(5445): 1741-1744.

This work is published under the standard license to publish agreement. After 12 months the work will become freely available and the license terms will switch to a Creative Commons AttributionNonCommercial-Share Alike 3.0 Unported License.

Supplementary Information accompanies this paper on British Journal of Cancer website (http://www.nature.com/bjc) 